\title{
Maximum Voluntary Ventilation in a Population Residing at 2,240 Meters Above Sea Level
}

\author{
Silvia Cid-Juárez MD MSc, Rogelio Pérez-Padilla MD, Luis Torre-Bouscoulet MD MSc, \\ Paul Enright MD, Laura Gochicoa-Rangel MD MSc, Daniel Cortés-Medina MD, \\ Peter Eliud Bapo-López MD, Marco Vinicio Tafolla-Manzo MD, and \\ Sergio Manuel Grave Díaz MD
}

\begin{abstract}
BACKGROUND: Measured maximum voluntary ventilation (MVV) correlates with maximum ventilatory capacity during exercise. As a shortcut, MVV is often estimated by multiplying measured $\mathrm{FEV}_{1}$ times 35 or 40 , but this index varies with altitude due to reduced air density. The objective was to describe MVV in healthy individuals residing at $2,240 \mathrm{~m}$ above sea level and compare it with the reference values customarily employed. METHODS: We recruited a convenience sample of respiratory-healthy, non-obese volunteers $>10 \mathrm{y}$ of age who had resided for $>2 \mathrm{y}$ in Mexico City. All participants performed forced spirometry and MVV according to current standards. Multiple regression models were fitted, including age, height, and measured $F E V_{1}$, separately for males and females to obtain reference values. The impact of lower air density on MVV at this elevation was estimated from the reported increase in peak flow in relation to altitude. RESULTS: We studied 381 individuals (210 females [55.1\%]) age 10-80 y with a mean MVV of $145.6 \pm 48 \mathrm{~L} / \mathrm{min}$. Both $\mathrm{FEV}_{1} \times 35$ and $\mathrm{FEV}_{1} \times 40$ underestimated the MVV observed: in males by approximately $26 \%$ and in females by approximately $10 \%$. MVV for our population approached $\mathrm{FEV}_{1} \times 45(98 \pm 15.6 \%$ of real MVV). Multiple regression models including height, weight, and measured $\mathrm{FEV}_{1}$ explained $70 \%$ of residual variability once sex was taken into account. CONCLUSIONS: At an altitude of $2,240 \mathrm{~m}, \mathrm{MVV}$ is about 45 times the measured $\mathrm{FEV}_{1}$, and it can be estimated for other altitudes. The best predicting equations for MVV were calculated separately for females and males and included the following predictors: age, age $^{2}$, and measured $\mathrm{FEV}_{1}$. The study found that reference values for MVV from studies conducted at sea level are inaccurate at this altitude. Key words: maximum voluntary ventilation; altitude; air density; exercise. [Respir Care 2017;62(12):1588-1593. ㅇ 2017 Daedalus Enterprises]
\end{abstract}

\section{Introduction}

The study of lung function is key for the diagnostic evaluation and monitoring of patients with respiratory dis-
Drs Cid-Juárez, Pérez-Padilla, Torre-Bouscoulet, Gochicoa-Rangel, Cortés-Medina, Bapo-López, Tafolla-Manzo, and Díaz are affiliated with the Department of Respiratory Physiology, National Institute of Respiratory Diseases (INER), Mexico City, Mexico. Dr Enright is affiliated with the Department of Medicine, University of Arizona, Tucson, Arizona.

Dr Cid-Juárez presented a version of this paper at the European Respiratory Society Conference, held September 26-30, 2015, in Amsterdam, Netherlands. eases and in assessing surgical risk, disability, and prognoses. Measuring maximum voluntary ventilation (MVV) is one of the tests used to evaluate respiratory mechanics.

\footnotetext{
The authors have disclosed no conflicts of interest.

Supplementary material related to this paper is available at http:// www.rcjournal.com.

Correspondence: Silvia Cid-Juarez MD MSc, National Institute of Respiratory Diseases, Calzada de Tlalpan 4502, Col. Sección XVI, Deleg. Tlalpan, Mexico City 14080, Mexico. E-mail: scidj@hotmail.com.
}

DOI: $10.4187 /$ respcare.04939 


\section{Reference Equation for Predicting MVV}

It is relatively simple and reproducible and can be performed with most spirometers. MVV correlates with maximum ventilation achievable during exercise, and residual respiratory reserve is routinely employed to interpret exercise tests. According to current diagnostic algorithms, a decrease in the value of the residual respiratory reserve indicates lung disease if $\mathrm{FEV}_{1}$ is low and indicates neuromuscular disease or poor effort if it is normal. ${ }^{1-4}$

Expected MVV values, usually based on sea-level reference values, 2,3 may fail at higher altitudes because the reduced air density increases forced respiratory flows. In addition, spirometric values from residents of Mexico City differ from those reported in developed countries, including Mexican-American populations..$^{5-7}$ Because inadequate reference values lead to errors in interpretation, our aim was to establish proper reference values for MVV in a population residing at 2,240 $\mathrm{m}$ above sea level and then compare them with published reference values to determine whether adjusting sea-level values for air density explains the differences in MVV measured in healthy people.

\section{Methods}

The study protocol was approved by the institutional ethics committee, and the adults or parents of the children who participated signed a letter of informed consent. Testing was conducted from May 2013 to August 2014 at the Pulmonary Function Testing Laboratory of the National Institute of Respiratory Diseases (INER) in Mexico City, a reference center for respiratory diseases that attends primarily patients who have no social security or other health insurance coverage. We included Mexican male and female individuals residing in the Metropolitan Area of Mexico City $(2,240 \mathrm{~m}$ above sea level), $>10 \mathrm{y}$ of age, neversmokers $(<400$ cigarettes smoked in lifetime), without previous respiratory diseases (COPD, chronic bronchitis, asthma, chest surgery, regular use of respiratory medications) or respiratory symptoms (wheezing, dyspnea, coughing, phlegm), and non-obese (body mass index $<30 \mathrm{~kg} / \mathrm{m}^{2}$ in individuals $>18 \mathrm{y}$ old and in the $<95$ th percentile of Centers for Disease Control and Prevention values in younger individuals). ${ }^{6}$

Participants were selected by invitation or through posters, mostly from among INER employees, their relatives, and students (of medicine, respiratory care, and nursing) enrolled in courses at our institution. No participants were active in competitive sports. Ethnic origin is usually not included in surveys applied in Mexico City, and all participants were considered to be Mexican mestizos.

Spirometry tests and MVV were performed with pneumotachograph-based equipment (Ergospirometry 5.22.1.149, CareFusion, San Diego, California) according to American Thoracic Society/European Respiratory Society standards. ${ }^{1}$ All tests were performed by experienced

\section{QUICK LOOK}

\section{Current knowledge}

Instead of measuring maximum ventilatory capacity (MVV) before performing a cardiopulmonary exercise test, it is often recommended to estimate MVV by multiplying $\mathrm{FEV}_{1}$ times 35-40; however, this recommendation does not take into account the changes in air density that occur at altitudes and may increase MVV.

\section{What this paper contributes to our knowledge}

Our study reveals that the recommended prediction strategies underestimated the MVV of a population residing at moderate altitude. At the elevation of Mexico City $(2,240 \mathrm{~m}$ above sea level), the MVV was very close to $\mathrm{FEV}_{1} \times 45$ and thus could be estimated for other altitudes.

trained personnel certified by the National Institute of Occupational Safety and Health after completing spirometry courses at the INER training site. We utilized reference values for spirometry obtained in Mexican-American individuals. ${ }^{5}$ The volume accuracy of the instrument was verified daily using a 3.00-L calibration syringe.

Briefly, the technician explained and demonstrated the maneuver to all participants. Subsequently, the maneuvers were performed with subjects seated and wearing a nose clip. Each maneuver consisted of at least 3 tidal breaths followed by breathing as fast and as deeply as possible for $12 \mathrm{~s}$. The 12-s ventilation observed was multiplied by 5 to obtain MVV at $1 \mathrm{~min}$. Additional maneuvers were carried out until the highest $2 \mathrm{MVV}$ values matched each other within $10 \mathrm{~L} / \mathrm{min}$. The highest of the $3 \mathrm{MVV}$ results was reported. ${ }^{1}$

\section{Statistical Analyses}

Descriptive statistics (means $\pm \mathrm{SD}$ ) were utilized to characterize the study population. Linear regression models were employed to predict MVV utilizing the following independent variables: age (crude, but also age ${ }^{2}$ and age ${ }^{3}$ because we included individuals during growth with increasing MVV and adults with decreasing MVV due to aging), height, weight, sex, and measured $\mathrm{FEV}_{1}$. Variables significantly associated with MVV in the univariate models were then incorporated into multivariate models to test fit with and without measured $\mathrm{FEV}_{1}$, to generate predicting equations for the case in which $\mathrm{FEV}_{1}$ was not measured. For each model, we observed the determination coefficient, $\mathrm{r}^{2}$, and the SD of the residuals (root mean square error) as general indicators of the model's fit. We compared the MVV measured in of the participants with common reference values employing a graphic smoothing technique, locally weighted scatterplot smoothing, to observe 


\section{Reference Equation for Predicting MVV}

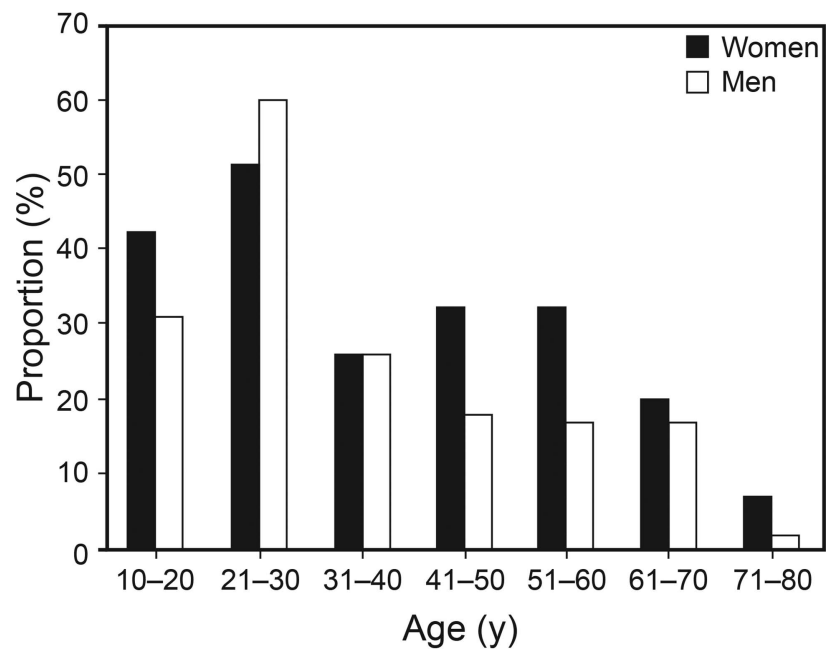

Fig. 1. Subject distribution by age and sex.

relationships among variables and their tendencies. Also evaluated was the appropriateness of estimating MVV as FEV times 35 or 40 , as is commonly recommended, ${ }^{7}$ before com- paring our MVV measurements with several reference values. ${ }^{8-13}$ Statistical analyses were performed with Stata 13 statistical software (StataCorp, College Station, Texas).

\section{Results}

We studied a total of 381 healthy residents of Mexico City age $9-81$ y, including 210 females (55.1\%). Mean age was $36.3 \mathrm{y}$, and body mass index was $24 \pm 4.2 \mathrm{~kg} / \mathrm{m}^{2}$ (Fig. 1 and Table 1). Potential participants who responded to an invitation to participate in the study were predominantly young adults with only a small proportion of elderly men and women. Subjects had $\mathrm{FEV}_{1}, \mathrm{FVC}$, and $\mathrm{FEV}_{1} / \mathrm{FVC}$ expressed as a percentage of prediction within normal range and similar in females and males. Table 1 depicts MVV in $\mathrm{L} / \mathrm{min}$ and as a percentage of predicted from several reference equations, with percentages considerably above the expected $100 \%$ (for properly adjusted reference equations), but also significant betweensex differences (all $P<.001$ ). Although $\mathrm{FEV}_{1} \times 45$ or $\mathrm{FEV}_{1} \times 40 \times 1.11$ (altitude adjusting factor; see the

Table 1. Baseline Characteristics of the Population

\begin{tabular}{|c|c|c|c|c|}
\hline Characteristics & Total Population $(N=381)$ & Males $(n=171)$ & Females $(n=210)$ & $P$ (Males vs Females) \\
\hline Age, y & $36.3 \pm 17.8$ & $34.7 \pm 16.9$ & $37.6 \pm 18.3$ & $<.001$ \\
\hline Height, m & $1.61 \pm 0.11$ & $1.68 \pm 0.10$ & $1.55 \pm 0.08$ & $<.001$ \\
\hline Weight, kg & $65.3 \pm 14.3$ & $72.1 \pm 14.4$ & $59.8 \pm 11.6$ & $<.001$ \\
\hline BMI, $\mathrm{kg} / \mathrm{m}^{2}$ & $24.9 \pm 4.2$ & $25.2 \pm 3.9$ & $24.7 \pm 4.4$ & .24 \\
\hline $\mathrm{FEV}_{1} / \mathrm{FVC}$ & $0.83 \pm 0.05$ & $0.82 \pm 0.05$ & $0.83 \pm 0.05$ & .01 \\
\hline $\mathrm{FEV}_{1}, \mathrm{~L}$ & $3.27 \pm 0.91$ & $3.90 \pm 0.81$ & $2.76 \pm 0.61$ & $<.001$ \\
\hline FVC, L & $3.95 \pm 1.12$ & $4.75 \pm 1.00$ & $3.30 \pm 0.707$ & $<.001$ \\
\hline $\mathrm{FEV}_{1}, \% \mathrm{P} *$ NHANES & $103.5 \pm 12.9$ & $104.1 \pm 12.0$ & $103.0 \pm 13.6$ & .40 \\
\hline FVC, \%P NHANES & $103.2 \pm 12.5$ & $103.9 \pm 12.3$ & $102.7 \pm 12.6$ & .37 \\
\hline $\mathrm{FEV}_{1} / \mathrm{FVC}, \% \mathrm{P}$ NHANES & $98.6 \pm 9.8$ & $98.6 \pm 11.9$ & $98.6 \pm 7.7$ & .91 \\
\hline $\mathrm{MVV}, \mathrm{L} / \mathrm{min}$ & $145.6 \pm 48.1$ & $178.9 \pm 44.6$ & $118.2 \pm 30.4$ & $<.001$ \\
\hline IC, L & $3.08 \pm 0.83$ & $3.68 \pm 0.76$ & $2.60 \pm 0.49$ & $<.001$ \\
\hline $\operatorname{MVV}\left(\% \mathrm{P} 35 \times \mathrm{FEV}_{1}\right)$ & $126.3 \pm 20.0$ & $131.0 \pm 20.4$ & $122.4 \pm 18.9$ & $<.001$ \\
\hline $\operatorname{MVV}\left(\% \mathrm{P} 40 \times \mathrm{FEV}_{1}\right)$ & $110.5 \pm 17.5$ & $114.6 \pm 17.8$ & $107.1 \pm 16.6$ & $<.001$ \\
\hline $\operatorname{MVV}\left(\% \mathrm{P} 45 \times \mathrm{FEV}_{1}\right)$ & $98.2 \pm 15.6$ & $101.9 \pm 15.8$ & $95.2 \pm 143.7$ & $<.001$ \\
\hline $\mathrm{MVV}, \% \mathrm{P}^{15}$ & $101.0 \pm 26.4$ & $127.1 \pm 13.4$ & $78.2 \pm 5.8$ & $<.001$ \\
\hline $\mathrm{MVV} \% \mathrm{P}^{13}$ & $134.1 \pm 28.8$ & $157.4 \pm 25.9$ & $114.8 \pm 11.8$ & $<.001$ \\
\hline MVV \% $\mathrm{P}^{11}$ & $115.8 \pm 24.3$ & $135.4 \pm 18.6$ & $99.4 \pm 14.3$ & $<.001$ \\
\hline MVV \% $\mathrm{P}^{10}$ & $129.3 \pm 44.0$ & $175.5 \pm 1.9$ & $88.3 \pm 8.5$ & $<.001$ \\
\hline $\mathrm{MVV} \% \mathrm{P}^{9}$ & $116.9 \pm 23.2$ & $136.0 \pm 19.9$ & $100.7 \pm 9.3$ & $<.001$ \\
\hline $\operatorname{MVV}\left(\% 40 \times \mathrm{FEV}_{1} \times\right.$ air density factor 1.11$)$ & $99.3 \pm 15.7$ & $102.9 \pm 16.0$ & $96.2 \pm 14.9$ & $<.001$ \\
\hline MVV, \%P, this study & $99.97 \pm 14.1$ & $99.98 \pm 13.8$ & $99.97 \pm 14.4$ & .99 \\
\hline \multicolumn{5}{|c|}{$\begin{array}{l}\text { Results are means } \pm \text { SD. } P \text { was estimated by } t \text { test for independent groups. } \\
\text { *\%P represents maximum voluntary ventilation of participants expressed as percent predicted for several estimations or reference equations. Three were based on } \mathrm{FEV}_{1}\left(\mathrm{FEV}_{1} \times 35, \mathrm{FEV}_{1} \times 40\right) \\
\text { commonly recommended at sea level. Maximum voluntary ventilation, } \% \mathrm{P} \text { (this study) was based on predicting equations from this study, including the measured FEV } \mathrm{FEV}_{1} . \mathrm{NHANES} \text {, reference values } \\
\text { by Hankinson et al }{ }^{5} \text { in Mexican-Americans. Air density factor } 1.11 \text { at Mexico City altitude is the increase in maximum voluntary ventilation expected for reduced air density because altitude } \\
\text { providing maximum voluntary ventilation behaves similarly as peak expiratory flow (see the online supplemental material). } \\
\text { BMI = body mass index } \\
\text { NHANES = National Health and Nutrition Examination Survey } \\
\text { MVV = maximum voluntary ventilation } \\
\text { IC }=\text { inspiratory capacity }\end{array}$} \\
\hline
\end{tabular}



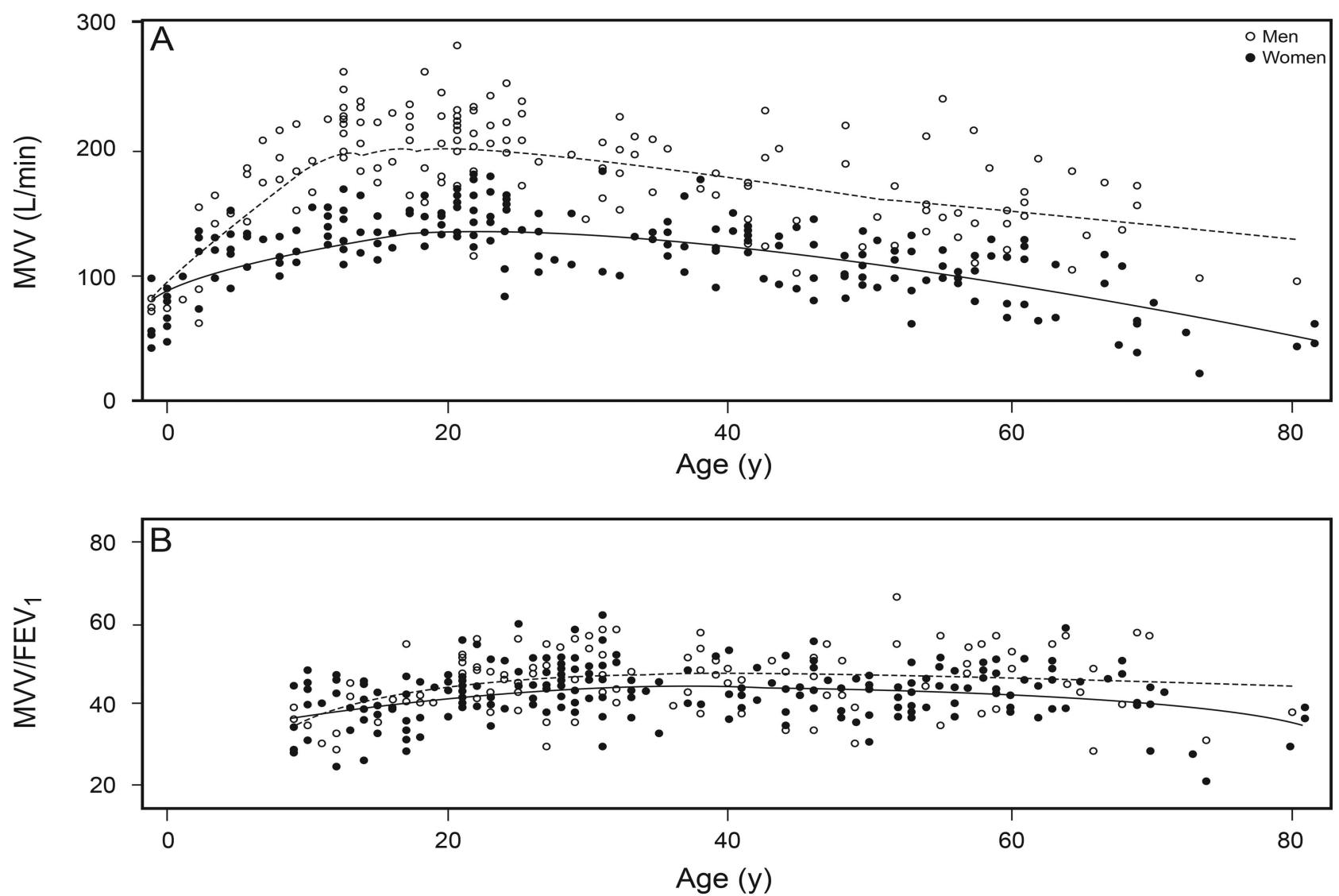

Fig. 2. Maximum voluntary ventilation $(M V V)(A)$ and $M V V / F E V_{1}(B)$ as a function of age. Measured $F E V_{1}$ considerably reduces age variation, which approaches 45 for nearly all ages. Results from males (circles) and females (filled circles) justify the practice of estimating MVV by multiplying measured $\mathrm{FEV}_{1}$ by a constant.

supplementary materials at http://www.rcjournal.com) in participants is near the average MVV, significant between-sex differences continue to exist, although they disappear upon applying the reference multiple regression equation (bottom line of Table 1).

Figure 2A depicts MVV as a function of age in males and females. It demonstrates increasing MVV (ascending curve on the left) and then aging (descending curve on the right), with higher values for males than females. When MVV was adjusted by measured $\mathrm{FEV}_{1}\left(\mathrm{MVV} / \mathrm{FEV}_{1}\right.$; Fig. 2B), age variations diminished significantly, as MVV and $\mathrm{FEV}_{1}$ increased and decreased more-or-less proportionally until showing an early horizontal distribution of points. As Table 1 shows, measured MMV was approximately 45 times the measured $\mathrm{FEV}_{1}$ (the exact value obtained by linear regression for both sexes together was $46.6 \times \mathrm{FEV}_{1}$; bottom line of Table 2).

Table 2 presents the regression coefficients of variables significantly associated with MVV, including the correlation $(r)$ and determination coefficients $\left(r^{2}\right)$. These variables plus age ${ }^{2}$ and age $^{3}$ were tested by multiple linear regression due to the curvilinearity of the relationship between age and MVV (Fig. 2A) and then fit-
Table 2. Regression Coefficients From Significant Univariate Predictors of Maximum Voluntary Ventilation

\begin{tabular}{lccc}
\hline \hline Predictors & $\beta$ & $\mathrm{r}$ & $\mathrm{r}^{2}$ \\
\hline Sex (male) & 60.7 & -0.63 & 0.39 \\
Age (y) & -0.66 & -0.25 & 0.06 \\
Height (m) & 325.9 & 0.77 & 0.58 \\
Weight (kg) & 1.68 & 0.50 & 0.25 \\
FEV $_{1}(\mathrm{~L})$ & 46.6 & 0.88 & 0.78
\end{tabular}

$\overline{\text { Sex was an important }}$ predictor of maximum voluntary ventilation, and multivariate predicting equations were fitted separately for males and females. The individual predictor most associated with maximum voluntary ventilation was the measured $\mathrm{FEV}_{1}$. All regression coefficients are statistically significant $(P<.001)$.

ted separately for males and females (Table 3), including equations with and without measured $\mathrm{FEV}_{1}$. The proportion of MVV variability explained by the models was $\sim 70 \%$ for those that included $\mathrm{FEV}_{1}$ and slightly below $60 \%$ for those that did not consider $\mathrm{FEV}_{1}$ (Table $3)$. Figures 3 and 4 summarize the study data (continuous line) and the MVV expected by different predicting equations ${ }^{9-15}$ (several also in Table 1) for males 


\section{Reference Equation for Predicting MVV}

Table 3. Best Multivariate Predicting Equations for Maximum Voluntary Ventilation With and Without Measured FEV 1

\begin{tabular}{lccccccc}
\hline \hline Equation & Constant & Age & Age $^{2}$ & Height $(\mathrm{m})$ & FEV $_{1}(\mathrm{~L})$ & $\mathrm{r}^{2}$ & Root MSE $^{2}$ \\
Male & -22.50 & 2.44 & -0.029 & & 40.80 & 0.69 & 25.21 \\
& -271.5 & 2.77 & -0.040 & 245.9 & & 30.24 \\
Female & 1.57 & 1.97 & -0.024 & & 32.32 & 0.71 & 16.39 \\
& -121.09 & 2.91 & -0.042 & 130.7 & & 0.58
\end{tabular}

Predicting equations are separated for males (top half) and females (bottom half). Predictors are presented in columns, and each row represents one equation. The first equation for males and for females represent the best predicting equations, both including the measured $\mathrm{FEV}_{1}$. The second equations for each sex represent the best equations without including the FEV $\mathrm{F}_{1}$, in case the latter was not measured. Weight was tested in the models but was not statistically significant and was eliminated from the final equations.

$\mathrm{MSE}=$ mean square error, the variation (SD) of residuals around the regression line; the equation with the lowest root mean square error is better

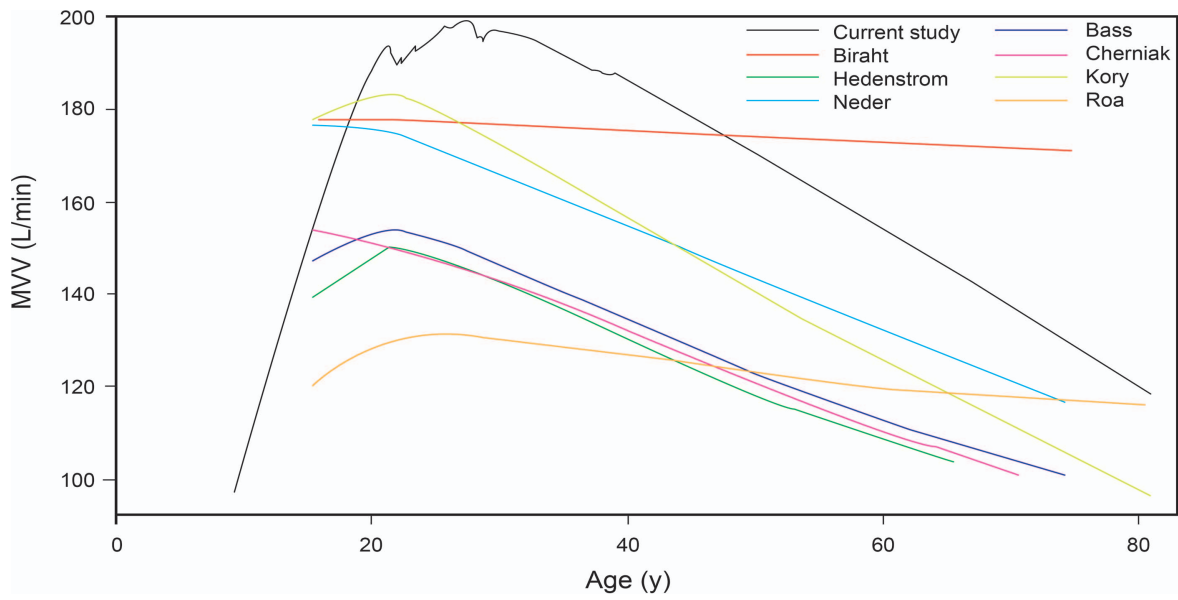

Fig. 3. Comparison of the observed measurements of maximum voluntary ventilation (MVV) in men from the current study with those expected from previously published studies for other populations. Equations basically involve the age-related decline in maximal voluntary ventilation but not the growth during childhood. In addition, predictions from the majority of equations are considerably below the measured values in Mexico City. Lines were obtained by smoothing of the data points using locally weighted scatterplot smoothing.

(Fig. 3) and females (Fig. 4). Lines represent smoothing (by locally weighted scatterplot smoothing) of the measured MVV and common reference equations.

\section{Discussion}

On average, MVV in Mexico City at 2,240 $\mathrm{m}$ above sea level was $126.3 \pm 20 \%$ of $\mathrm{FEV}_{1} \times 35$ and $110 \pm 17.5 \%$ of $\mathrm{FEV}_{1} \times 40$, as is commonly recommended before an exercise test to estimate MVV without performing the test, ${ }^{2,3}$ which is considered potentially fatiguing. In fact, MVV approached 45 times the measured $\mathrm{FEV}_{1}$ (yielding $98 \pm 15.6 \%$ of predicted), probably due to the lower air density at 2,240 $\mathrm{m}$ above sea level and the resulting higher flows during maneuvers that involved turbulence. The expected increase in peak expiratory flow in Mexico City compared with sea level and, probably, MVV due to lower air density was $11 \%,{ }^{7}$ which fits the measured data if we estimate predicted MVV at Mexico City as $40 \times \mathrm{FEV}_{1} \times 1.11$ (measured values were $99.2 \pm 15.7 \%$ of this estimate; see Table 1 of the supplementary material). A similar procedure could be used to estimate expected values for other altitudes. Because the predicting equation for changes in peak expiratory flow with altitude utilized a power function of barometric pressure (see Methods), an estimate based on altitude would be simpler, since from sea level to $3,000 \mathrm{~m}$, the calculated value is very close to a straight line: MVV correction factor $=1.0+(0.051 \times$ altitude $[\mathrm{km}])$ (see the supplementary material). ${ }^{7}$ Because adding measured $\mathrm{FEV}_{1}$ to the reference equations substantially improves their accuracy for predicting MVV, we recommend including the former if MVV is not measured directly.

Even in healthy individuals, estimates of predicted MVV may differ considerably from measured MVV $(-50$ to $+50 \mathrm{~L} / \mathrm{min}$ ). The coefficient of variation for MVV is $3.8 \%$ and $5.1 \mathrm{~L} / \mathrm{min}$, slightly higher than for FVC $(3.3 \%$ and $0.24 \mathrm{~L})$ and $\mathrm{FEV}_{1}(2.6 \%$ and $0.18 \mathrm{~L})$. Therefore, before cardiopulmonary exercise testing, we recommend measuring MVV instead of only estimating it from $\mathrm{FEV}_{1}$. In our experience, healthy individuals and patients can perform this maneuver properly without experiencing fatigue, dizziness, or coughing. 


\section{Reference Equation for Predicting MVV}

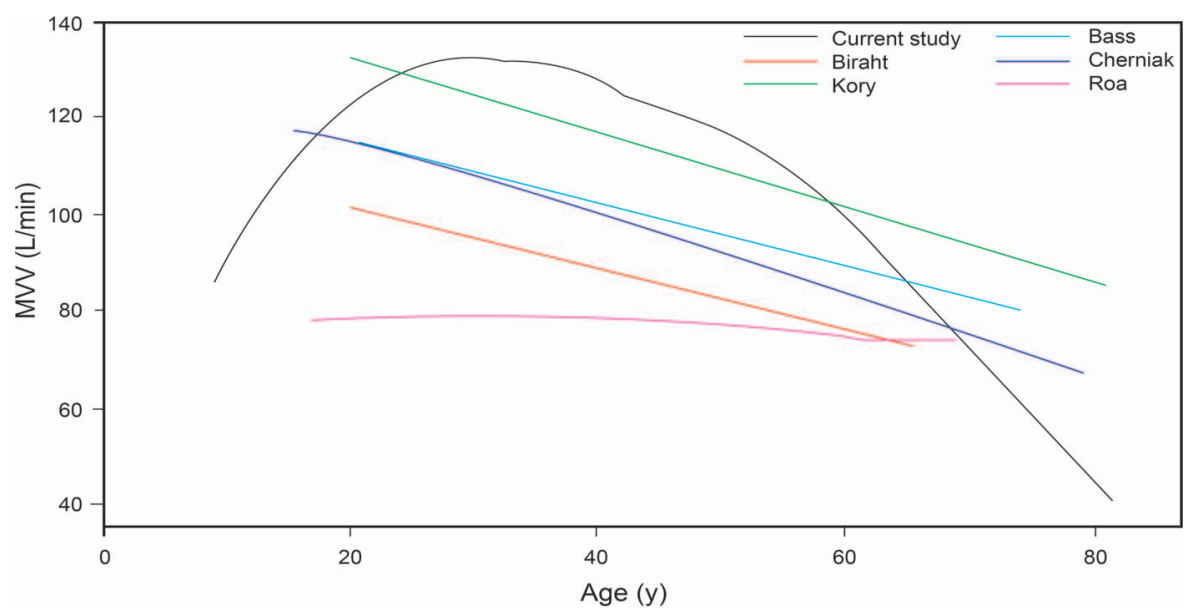

Fig. 4. Comparison of the observed measurements of maximal voluntary ventilation (MVV) in women from the current study with those expected from previously published studies for other populations. Equations basically involve the age-related decline in maximal voluntary ventilation but not the growth during childhood. In addition, predictions from the majority of equations are considerably below measured values in Mexico City. Lines were obtained by smoothing of the data points using locally weighted scatterplot smoothing.

Figures 2 and 3 synthesize the comparison of MVV measured in our study and common reference values. Average predicted values were below measured MVV in both males and females. In addition, the age-slope of several reference values was different from that of the individuals studied, especially the females. Finally, in Table 1, the MVV expressed as a percentage of predicted produced, in general, significantly higher values for males than females.

Several limitations of our study should be mentioned. Although the distribution of participants by age adheres to that observed in the Mexican population, the number of elderly individuals included was low, which could reduce the accuracy of our equations for older age groups. Also, participants formed a convenience sample, although they were healthy residents of Mexico City with a range of socioeconomic levels characteristic of that population. Gathering a populationbased sample representative of Mexico was not feasible, but also probably unnecessary to demonstrate the change in MVV with altitude compared with previously reported sea-level values. Finally, once adjustment for $\mathrm{FEV}_{1}$ was performed, variations of MVV with age were small.

\section{Conclusions}

Published equations and prediction strategies for MVV do not apply to individuals residing at moderate altitudes. Results in Mexico City were approximated by $\mathrm{FEV}_{1} \times 45$, but this is expected to change at other altitudes. We therefore recommend measuring MVV before cardiopulmonary exercise testing.

\section{REFERENCES}

1. Miller MR, Hankinson J, Brusasco V, Burgos F, Saburi R, Coates A, et al. Standardisation of spirometry. Eur Respir J 2005;26(2):319338.
2. Cotes JE, Chinn DJ and Miller MR. Lung function: physiology, measurement and application in medicine, 6th edition, Hoboken, New Jersey: Wiley-Blackwell; 2006:130-142.

3. Gandevia B, Hugh-Jones P. Terminology for measurements of ventilatory capacity. Thorax 1957;12(4):290-293.

4. Mottram C. Ruppel's manual of pulmonary function testing, 10th edition. Maryland Heights, Missouri: Mosby Elsevier; 2013:64-66.

5. Hankinson JL, Odencrantz JR, and Fedan KB. Spirometric reference values from a sample of the general U.S. population. Am J Respir Crit Care Med 1999;159(1):179-187.

6. Kuczmarski RJ, Ogden CL, Guo SS, Grummer-Strawn LM, Flegal KM, Mei Z, et al. 2000 CDC growth charts for the United States: methods and development. Vital Health Stat 11 2002;246:1-190.

7. Martínez-Briseño D, Fernández-Plata R, Gochicoa-Rangel L, TorreBouscoulet L, Rojas-Martínez R, Mendoza L, et al. Longitudinal lung function growth of Mexican children compared with international studies. PLoS One 2013;8(10):e77403.

8. Barr RG, Stemple KJ, Mesia-Vela S, Basner RC, Derk SJ, Henneberger PK, et al. Reproducibility and validity of a handheld spirometer. Respir Care 2008;53(4):433-441.

9. Bass H. The flow volume loop: normal standards and abnormalities in chronic obstructive pulmonary disease. Chest 1973;63(2):171-176.

10. Birath G, Kjellmer I, Sandqvist L. Spirometric studies in normal subjects II: ventilatory capacity test in adults. Acta Med Scand 1963; 173(2):193-198.

11. Cherniack RM, and Raber MB. Normal standards for ventilatory function using an automated wedge spirometer. Am Rev Respir Dis 1972;106(1):38-46.

12. Hedenström H, Malmberg P, and Fridriksson HV. Reference values for lung function tests in men: regression equations with smoking variables. Ups J Med Sci 1986;91(3):299-310.

13. Kory RC, Callahan R, Boren HG, and Syner JC. The Veterans Administration-Army cooperative study of pulmonary function. I. Clinical spirometry in normal men. Am J Med 1961;30:243-258.

14. Neder JA, Andreoni S, Lerario MC, Nery LE. Reference values for lung function tests. II. Maximal respiratory pressures and voluntary ventilation. Braz J Med Biol Res 1999;32(6):719-727.

15. Roa CC, Zaldivar CA, Salonga R, Bobadilla J, Lansang MA, Reodica R, et al. Normal standards for ventilatory function tests in adult Filipinos. Philipp J Int Med 2013;51(1):185-194. 